\title{
Gender-Bias and Its Impact on the Perceived Professional Success of Exceptionally Talented Women: A Group Decision-Making Study
}

\author{
Eduardo R. Infante \\ University of Seville, Spain
}

\author{
Emilia Bairamova \\ Future Planet, London, UK
}

\begin{abstract}
Studies on intellectual giftedness highlight a strong gender discrimination tendency in the case of gifted females both in detection and in their further academic support. The relationship between gender roles and their influence on gender-biased attribution of success is considered. Influenced by gender socialization processes, the closer to fulfill the pre-assigned gender role a female is, the weaker the social perception of her as being potentially gifted is, regardless of her age, personal vocation, and/or actual talent. To support this idea, 128 respondents clustered in focus groups were asked to suggest suitable career pathways for four concocted women based on their personal and academic profiles, where only two of them perfectly matched the preconceived expectations of feminine gender role (i.e., feminine traits and attractiveness). Additionally, four male profiles were also provided for comparison purposes. It became apparent that gifted women, who live up to the stereotypical ideals associated with their gender, are underrated, discouraged from their vocations, and even misperceived as unapt. However, perception of gifted men was not influenced to the same degree by whether or not they embody their masculine gender traits.
\end{abstract}

Keywords: giftedness, socialisation, gender sex-roles, attractiveness, studies

\section{Introduction}

Social discrimination towards women remains an unspoken issue affecting both professional and personal lives of modern women. The underlying causes of this gender bias have been long based on the socially constructed division of labour, i.e., production and reproduction, and their subsequent impact on the distribution of gender roles between men and women, respectively (Ortner, 1974; Sacks, 1979; Rosaldo, 1980; Davison \& Burke, 2000). Anthropological roots of this historical practice can be traced through vocation and work theories that have turned gender into a structural irrational variable and, as a result, conditioned the labour market (Infante, 2011). Research shows that the socialisation process seems to have had an alienating effect on women from its early stages, limiting their chances of self-realisation. This highly rigid definition of male and female roles is based on a pre-established set of social assumptions that lack scientific reasoning. For instance, the deeply-rooted socio-anthropological preconceptions of division of labour continue to influence the nature of work based on the

Eduardo R. Infante, associate professor, Ph.D., Mphil, Faculty of Psychology, University of Seville, Spain.

Emilia Bairamova, business development director, MA Fashion Design Technology, Future Planet, London, UK. 
gender of work (Osca \& López-Sáez, 1994; Peiró, Prieto, \& Roe, 1996). The gender of work assigns men to instrumental-agent roles (e.g., architects, politicians, high-ranking managers, or soldiers), where they can apply themselves creatively and make an active impact on the overall workflow. This gender-biased social conditioning that dates back to the early days of the socialisation processes allows men to feel more empowered and in control at work. On the contrary, women are often assigned to expressive-communal positions (e.g., nurse, cabin crew, model, or secretary). From a naturalisation point of view, this limits women to roles that are based on their gender-associated traits, such as tenderness, affection, and empathy.

Oversimplified neurological theories, for instance, also suggest that men are more likely to be left-brain dominants and thus more suitable for more demanding jobs as they appear to be more logical, analytical, and objective. Consequently, women, who are socially perceived as more intuitive, thoughtful, and subjective (right-brain dominants), are considered less compatible with the androcentrically-defined working world. In summary, socialisation processes shape male and female work roles through the acquisition of beliefs, behaviours, and values deemed significant and appropriate by the more dominant members of societies, i.e., men (Shaffer, 1988; Webster, 1979; Silverman \& Miller, 2009).

Despite the gender equity in terms of the social development of societies, women are still considered incapable of working in male-dominated industries and occupations. This forces them to seek less competitive positions and often give up on prospects of successful career development (Infante, 2011). Studies show that gifted women wishing to pursue male-dominated roles are particularly vulnerable. From an early age, girls are conditioned to seek social validation and acceptance. Those, who grow up attempting to defy the imposed social stigma by not conforming to the expected gender role in pursuit of individualism, power, and financial independence, face a distressing dilemma. Consequently, it is common for the over-achieving women to develop the so-called impostor syndrome because of their inability to internalise their accomplishments based on the fear of betraying their socially-accepted gender role and being perceived as a "fraud" (Clance \& Imes, 1978; Kline \& Short, 1991). The impostor syndrome tends to heighten the tendency in women to underestimate themselves and leads to the hubris-humility effect, where "hubris" stands for male and "humility" for female (see Storek, 2011).

Both the gender of work and the impostor syndrome condition women's professional lives, affecting both personality and career-related decisions. Researchers have found strong evidence suggesting that gifted women hide their true capabilities and intelligence (Kerr, 1985; Bell, 1989; Buescher \& Higham, 1989; Reis \& Callahan, 1989). It is often impossible for women to challenge the pre-established gender pathways at work, leaving them no choice but to imitate male traits through homosocial reproduction (Elliott \& Ryan, 2004). As safe and non-confrontational as the choice might be, it also limits both women and the organisations from implementing the feminisation of the workplace practices (see Infante, 2011). Furthermore, research shows that only three out of 10 identified gifted students are female and the rate is even lower in the cases of adult genius (Dominguez Rodríguez, 2002; 2003; Infante, 2015). In adulthood, chances of women to be chosen for higher positions over their male colleagues continue to remain low despite the clear evidence of their capabilities and talents. As a result, an overwhelming number of reports continue to highlight that women face serious discrimination when it comes to wages (wage gap) and access to jobs (glass-ceiling effect), whilst working men benefit from gender bias (Schein, 1973; Grant \& Eiden, 1982; Taliff, 1991; Maume, 1999; Wirth, 2001; Blau \& Khan, 2003).

Female intellectual giftedness goes unnoticed because of the global acceptance of androcentric socialisation 
practices (Reis \& Callahan, 1989; Reis, 1998; Kerr \& Cohn, 2001; Lips, 2006). Consequently, females are socially perceived as less intellectually capable of holding high-ranking roles. While selection processes in organisations should guarantee equal employment opportunities, it only takes seven seconds to discriminate against someone because of their gender. One of the most salient variables of gender bias, when it comes to job screening, is female beauty and the overall physical attractiveness. Time and again, from teen magazines to television programmes women are continuously bombarded with the predetermined ideals of beauty. Women are inconspicuously brainwashed to preserve their youthful appearances at all costs until the message becomes ingrained in them (Reis, 1998). Beauty creates an alienating social barrier for gifted women, who would attempt to deny (or suppress) their natural assets in order to excel and flourish intellectually. The allure of unrealistic and superficial images of female bodies breeds an unhealthy fallacy that pushes women to seek social validation and to conform. The heavy weight of such unattainable expectations can undermine women's confidence in a workplace. The reported case of Debrahlee Lorenzana, who was forced out of her Manhattan Citibank job because she was too good looking, serves to illustrate the point. Debrahlee was told that "as a result of her tall stature, coupled with her curvaceous figure, she should not wear classic high-heeled business shoes, as this purportedly drew attention to her body in a manner that was upsetting to her easily distracted male managers" ( $E l$ País, 2010). As stated by Eilman and Saruwatari (1979), attractiveness consistently proved to be an advantage for men, but in case with women benefited them only when seeking non-managerial positions. Female and male applicants received lower ratings when being considered for the opposite-sex jobs, and the difference between the ratings of males and females decreased, the more job-specific information was provided.

In this study, we address the relationship between gender roles and the perception of professional eminence in gifted women. We hypothesise that the closer to full a stereotypical female gender role a woman is, the greater the discrimination towards her is regardless of the actual evidence of her giftedness and wished professional career target.

\section{Research}

Using the Bem Sex-Role Inventory (BSRI; Bem, 1974), four academic profiles were created for each sex. All eight profiles shared the same vocational interests and personalities and each one of them depicted an exemplary highly skilled student. Instructions were given to decide in groups the best study paths for future career of the proposed students, as follows:

\footnotetext{
"Although there are not many options in her (his) residential area, s(he) would like to work in the field of Industrial Engineering or alike, because s(he) would like to apply her(him)self in Maths and Physics. S(he) enjoys writing, listening to music, going out and dancing with friends in her (his) free time".
}

The only differentiator between the profiles was the level of physical attractiveness (high vs low) and their gender-specific personality traits (femininity vs masculinity based on BSRI). In order to quantify attractiveness, respondents had to rate students' ID pictures (pre-randomly retrieved from the Internet) on a ten-point scale after the experiment. The outcomes seemed to have supported the hypothesis regarding the perception of beauty and resulted in a strong divide ( 8.80 versus $5.72, \mathrm{t}=0, \mathrm{p}<.01, \mathrm{n}=128$ ). BSRI served to describe students' personalities based on their stereotypical gender attributes, such as feminine (female-sex-role) and masculine (male-sex-role): 
Feminine: Tender, sensitive to other's needs, compassionate, affectionate, sympathetic, warm, gentle, loves children, emotionally vulnerable, cries easily.

Masculine: Athletic, strong personality, willing to take risks, dominant, rather aggressive, acts as a leader, individualistic, forceful, and ambitious.

After the discussion, respondents were asked to reach an agreement as a group on which professional or educational pathways would best suit the profiles based on the following career options currently available on the labour market:

(1) Nurse;

(2) Lawyer;

(3) Cabin crew;

(4) Architect;

(5) Doctor;

(6) Researcher at a pharmaceutical company.

Based on the existing theories of gender-biased division of labour, it was safe to assume that women would be assigned to secondary, less dominant roles that are conventionally more suitable for females (Osca \& López-Sáez, 1994; Bourdieu, 1999; 2000; Blackburn, Browne, Brooks, \& Jarman, 2002). Therefore, we expected respondents to assign female profiles career pathways 3,1 , and 2 , and in that given order. The experimental design provided us with eight experimental conditions that differed in the degree of their proximity to the stereotypical gender roles (see Table 1).

Table 1

Experimental Conditions of the Research Crossing (1) Sex, (2) Personality Traits Based on BSRI, and (3) Physical Attractiveness

\begin{tabular}{llllll}
\hline & \multicolumn{2}{c}{ FEMALE } & & \multicolumn{2}{c}{$\begin{array}{c}\text { MALE } \\
\text { (Contrast group) }\end{array}$} \\
\cline { 2 - 3 } \cline { 5 - 6 } & High attractiveness & Low atrractivenes & & High attractiveness & Low atractivenes \\
\hline Feminine profile & $\mathrm{C} 1$ & $\mathrm{C} 2$ & $\mathrm{C} 3$ & $\mathrm{C} 4$ \\
Masculine profile & $\mathrm{C} 5$ & $\mathrm{C} 6$ & $\mathrm{C} 7$ & $\mathrm{C} 8$ \\
\hline
\end{tabular}

Notes. Totally matched conditions (with gender): C1 \& C8; Partially matched conditions: C2, C5 \& C4, C7; Totally mismatched conditions: $\mathrm{C} 6$ \& $\mathrm{C} 3$.

The respondents' decisions were measured by the perception of future success (PFS) index. In order to evaluate which their choices of matching profiles with jobs were weighed against the impartial and unbiased decision making variables that would have been gender and attractiveness neutral. In order to quantify the data, each variable was assigned value, where the expected answers were subtracted from the obtained ones, i.e., Architect $=1$, Researcher at a pharmaceutical company $=2$, Doctor $=3$, Lawyer $=4$, Nurse $=5$, and Cabin crew $=6$. As a result, the PFS scores - sums in absolute values - varied from 0 (equal rankings) to 18 (opposite rankings). For a more accurate reading, the final PFS was translated into a positive scale (ex. PFS $=18-\mathrm{PFS}$, where 0 is the worst group answer and 18 is the best). 


\section{Focus Groups}

\section{Sample}

A total of 128 students from three different university faculties (Psychology, Work Sciences, and Law) took part once in the 24 focus group sessions, three groups per experimental condition. The average age of participants was 22.3 y.o. (years old), of whom $15.6 \%$ were male. Their academic years varied from first to final.

\section{Process}

Participants' task was to discuss and outline/rank best academic options for a specific proposed student, who submitted his/her academic application in hope to pursue successful career opportunities. Focus group sizes varied between four and seven members, with discussions lasting 5.36 minutes on average (ranging from 2.35 to 6.08). No time restrictions were set and the researcher's instructions remained consistent throughout, upon delivering which he did not intervene in the discussion. Once the ranking was completed, each group member rated attractiveness of the student based on his or hers ID picture using a 10-point scale.

\section{Data Analysis}

Figure 1 depicts the general outcomes obtained during each experimental condition. It is evident that the average score of PFS amongst women was slightly higher than amongst men (4.6 vs 4.2), although this is not statistically significant. However, the experiment showed that the more attractive a female student was and the more she embodied the preconceived gender role, the less seemingly successful career choices were assigned to her despite the evidence of her academic achievements $(\mathrm{C} 1=1.0 / 18.0)$. Furthermore, female students who did not fulfil their expected gender roles in terms of attractiveness and femininity to a greater degree were suggested better career opportunities $(\mathrm{C} 6=7.4 / 18.0)$. The opposite outcomes were received when male student cases were reviewed, where good looks and definitive masculine traits guaranteed the perceived future success $(\mathrm{C} 8=$ $6.7 / 18.0)$ and lack of thereof led to a fewer opportunities $(C 4=2.0 / 18.0)$.

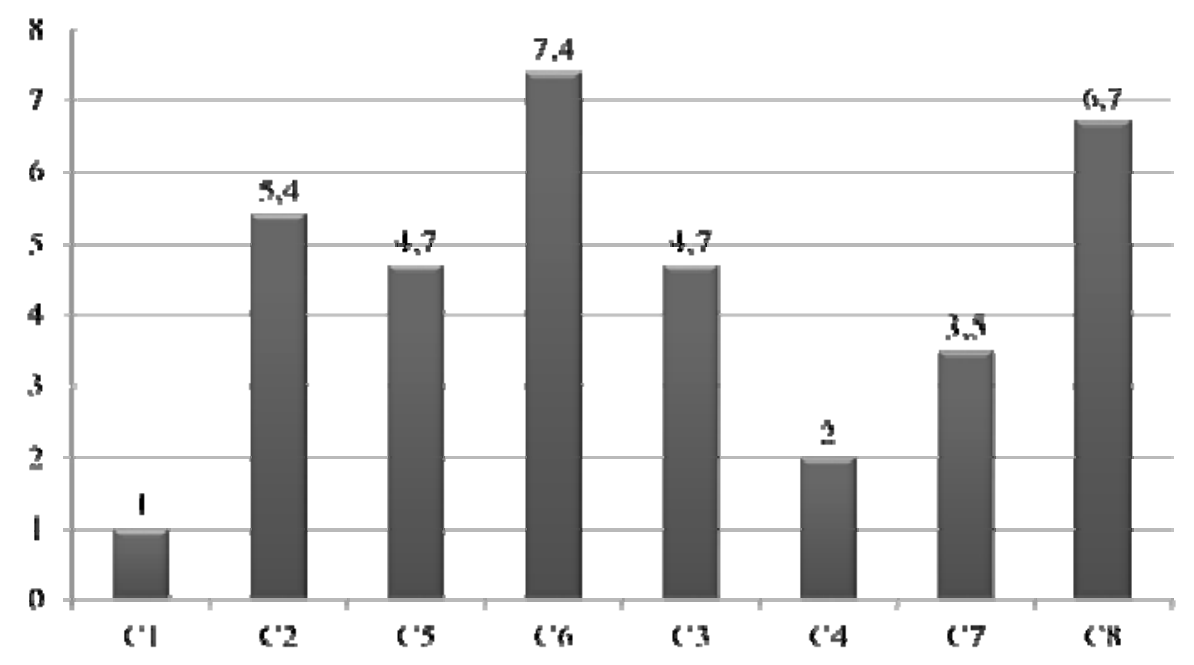

Women's cond.

Figure 1. Means of PFS index in each experimental condition. 
Additionally, it was proven that gifted women stand better chances of pursuing successful academic or professional careers if they are less attractive and adopt more masculine traits, whilst men are less likely to succeed if they are perceived handsome but possess dominant feminine traits.

As far as gender bias is concerned, gifted women faced serious discrimination unlike gifted men as limitations were placed on their capabilities because of their physical attractiveness (see Figure 2). Despite the minimal impact of attractiveness on PFS in the case of men (from 4.4 to 4.1), when it came to gifted women, being perceived as less beautiful was a significant determinant to be encouraged to adequate academic or professional success (from 2.4 to 6.6). Those chances were drastically reduced if she was considered pretty and were quickly assigned to roles that required little intellectual activity. The average loss of 4.2 in PFS was statistically significant $(\mathrm{Chi} 2=48.75, \mathrm{p}<.0000)$.

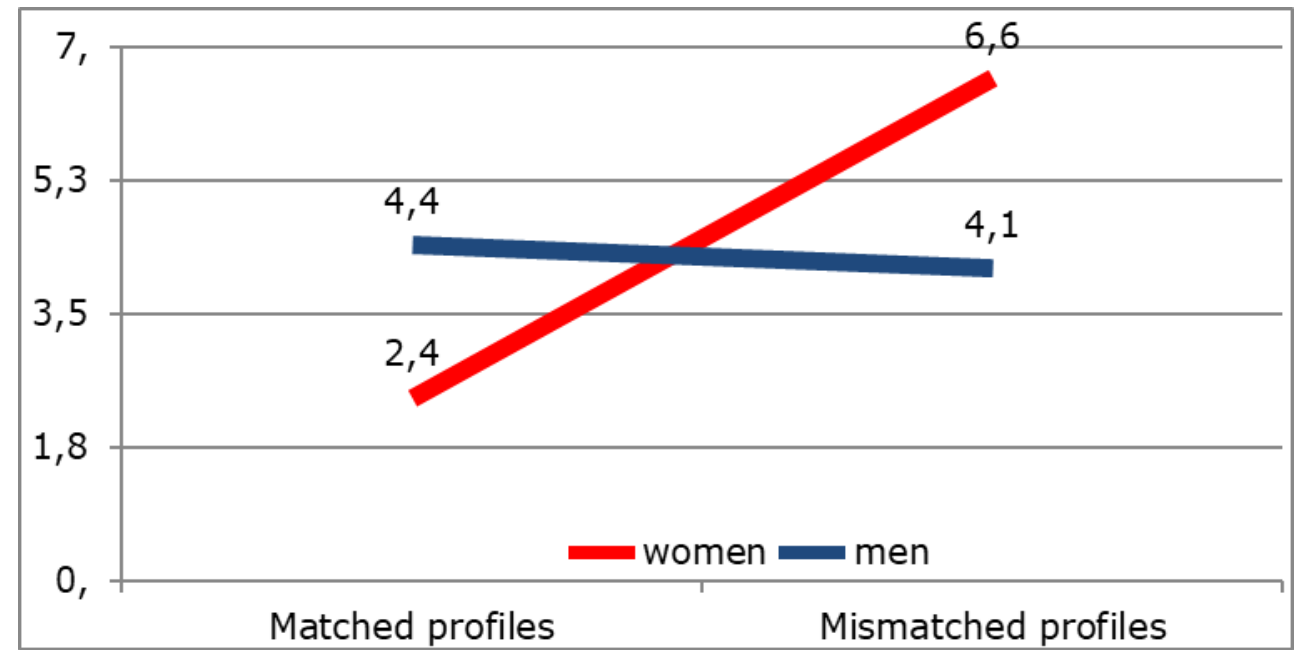

Figure 2. Average PFS index in (mis)matched profiles for attractiveness.

Similar results were obtained during the PFS evaluation based on personality-trait variables (see Figure 3). Outcomes from the focus groups showed that gifted women, who possessed the ideal feminine traits, as far as BSRI was concerned, were undervalued in terms of their actual potential or future career prospects. If they were considered too feminine, then PFS index lowered from 5.6 to 3.2 on average (difference of 2.4). In the case of gifted men, the more of the desired personality traits they matched, the higher their PFS index grew (from 3.4 to 5.1). While intragroup differences were not significant, the PFS means between sexes were statistically significant $($ Chi2 $=10.24, \mathrm{p}<.0013)$. 


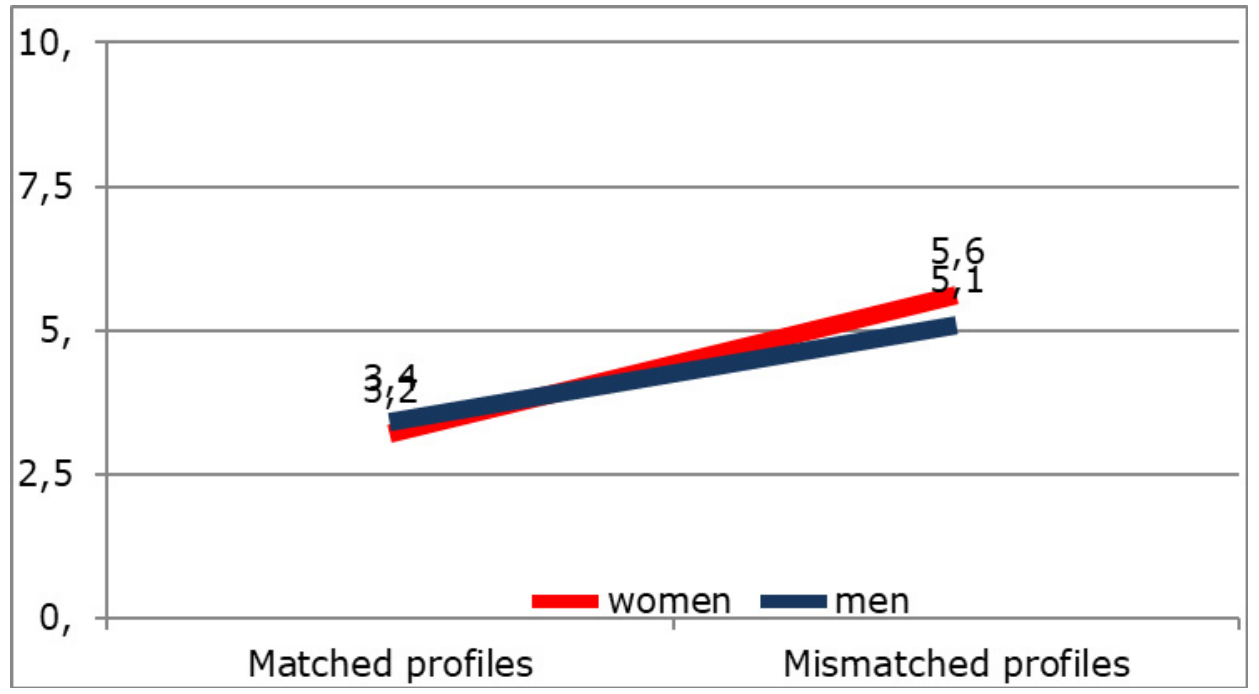

Figure 3. Average PFS index in (mis)matched profiles based on personality traits.

Mixed outcomes are presented in Figure 4 based on a more in-depth understanding of respondents' choices. In this case, we use partially matched profiles, where at least one independent variable (attractiveness or personality) differs from what is expected from both gender roles.

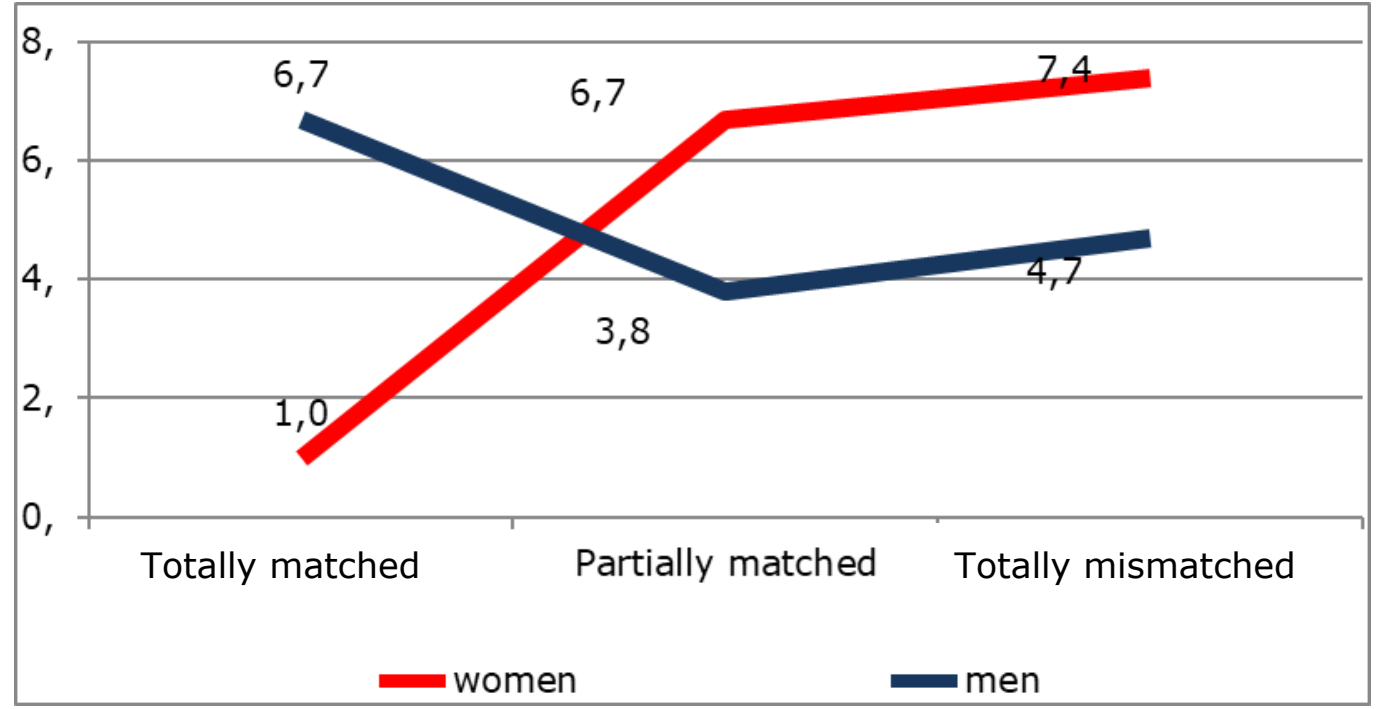

Figure 4. Average PFS index in (mis)matched profiles based on personality traits.

In the case of gifted women, the study confirms that those, who do not embody the stereotypical gender role, have better PFS indexes. Thus, partially matched female profiles levelled up with male ones when women deviated from the expected societal perception of their gender and were deemed more suitable for demanding jobs and better academic prospects. Consequently, completely mismatched profiles, i.e., "masculine women", behaviorally speaking, obtained the highest PFS score. Deviations from beauty and feminine traits multiplied PFS average by seven (from 1 to 7.4). For gifted men, the deviation from the expected gender role had lesser impact and only concerned men with more prominent feminine traits ("feminine men"). The study concludes that men's perceived professional or academic success was not affected by whether or not they met the stereotypical expectations of their gender role. These conclusions were statistically significant (Chi2 $=30.54, \mathrm{p}<.0003)$. 


\section{Discussion and Further Research}

The perception of future career success in gifted women was evaluated based on physical attractiveness and the preconceived gender role stereotyping. Research shows that the closer to fulfill a stereotypical female role (matching the profile) a gifted woman is, the more limitations in terms of academic or professional opportunities she faces for being perceived as "feminine". Despite the evidence of academic excellence or talents, gifted women with prominent feminine traits and good looks were overlooked and barely considered for career and educational pathways that were, on the other hand, suggested to gifted men. Furthermore, physical attractiveness had a negative effect when female applicants were considered for reputable jobs like architect, researcher, or doctor, even though students' profiles matched the requirements for the roles. On the contrary, attractiveness did not hinder the prospects of gifted men and both matching and mismatching male profiles were equally and objectively advised. According to data, gifted men were 5.7 times more likely to be "correctly" advised in comparison to gifted women, who displayed the traits expected of their gender (matching conditions). The findings also revealed a minor negative impact on the career prospects of men, who displayed feminine traits (mismatching profiles), but wished to pursue stereotypically masculine jobs. Nevertheless, gifted men with mismatching profiles were 2.7 times more likely to be considered for highly demanding jobs than gifted women. These results are consistent with the revised literature that reinforced the link between the social perception, gender socialisation, and the gender of work (Eilman \& Saruwatari, 1979; Silverman, 1995; Roeper \& Silverman, 2009). This study empirically validates a triple discrimination phenomenon that characterises women who possess talent, feminine traits, and physical attractiveness. To support the point, the research shows that gifted men were nearly 6 times more likely to be correctly advised than gifted women, whose attractiveness biased the decision-making process. Based on these findings, it seems that in order to build a successful career, gifted women should utilise their skills and capabilities (despite the high risk of potentially developing the impostor syndrome) and downplay their physical attractiveness along with the "socially inherited" feminine traits. The research shows that "masculine women" are 7 times more likely to be chosen for stereotypically male-dominated academic or professional pathways over "feminine women". The conclusive advice to talented women wishing to thrive in competitive professional or academic environments is to be more in control of their image. This can be achieved by opting for gender-neutral professional attire and moderate makeup, in order to soften their physical traits that can increase chances of gender bias. The aim is not to depersonalise a talented woman, but to make her image more acceptable to those who most control the recruitment and screening processes, i.e., men.

To conclude, further studies are required to continue analysing the more accurate impact of attractiveness and personality traits on career prospects and professional success. We have paid exclusive attention to the final outcomes of the decision-making focus groups and, in doing so, dismissed the events of the actual process: the content of group discussions and the dynamics of both genders within the groups. We have noticed, for instance, that male-only groups were more reluctant to assign gifted women to traditional male-dominated jobs than female-only groups. Whereas, in mixed groups women were more likely to conform to the pressure of male members by re-focusing discussions on irrelevant attributes, such as attractiveness. These facts may have influenced our results and should be addressed in the new research study using both quantitative and qualitative methodologies. 


\section{Conclusion}

Empirical data have been obtained and prove the existence of a triple social discrimination towards women who possess (1) talent, (2) feminine traits, and (3) physical attractiveness. While this discrimination discouraged young people's perceptions about professional success of exceptionally talented women, the same did not happen when guiding men with the same giftedness profiles. Tripe social discrimination (unconsciously) serves to slant women's career towards less intellectually demanding tasks and/or low-paying jobs to maintain the androcentric division of labour and women's beauty-centered self-esteem and, consequently making talent and physical attractiveness as rather incompatible.

\section{References}

Bell, L. A. (1989). Something's wrong here and it's not me: Challenging the dilemmas that block girls' success. Journal for the Education of the Gifted, 12(2), 118-130.

Bem, S. L. (1974). The measurement of psychological androgyny. Journal of Consulting and Clinical Psychology, 42, $155-162$.

Blackburn, R. M., Browne, J., Brooks, B., \& Jarman, J. (2002). Explaining gender segregation. British Journal of Sociology, 53(4), 513-536.

Blau, F. D., \& Kahn, L. M. (2003). Understanding international differences in the gender pay gap. Journal of Labor Economics, 21(1), 106-144.

Bourdieu, P. (1991). Language and symbolic power. Cambridge: Polity Press.

Bourdieu, P (2000). Pascalian meditations. Stanford, CA: Stanford University Press.

Buescher, T. M., \& Higham, S. J. (1989). A developmental study of adjustment among gifted adolescents. In J. Van Tassel-Baska and P. Olszewski-Kubilius (Eds.), Patterns of influence on gifted learners: The home, the self, and the school (pp. 102-124). New York: Teachers College Press.

Clance, P. R., \& Imes, S. A. (1978). The imposter phenomenon in high achieving women: Dynamics and therapeutic intervention. Psychotherapy: Theory, Research and Practice, 15(3), 241-247.

Davison, H. K., \& Burke, M. J. (2000). Sex discrimination in simulated employment contexts: A meta-analytic investigation. Journal of Vocational Behavior, 56, 225-248.

Domínguez Rodríguez, P. (2002). Sobredotación, mujery sociedad. In FAISCA, 8, 3-34.

Domínguez Rodríguez, P. (2003). La autoestima en niñas y adolescentes de altas habilidades (Self-esteem in gifted girls and adolescents). In P. Domínguez Rodríguez, L. Pérez Sánchez, E. Alfaro Gandarilla, and Ma . V. Reyzábal Rodríguez (Eds.), Mujer y sobredotación: Intervención escolar (pp. 135-138). Revista de Investigación e Innovación Educativa del Instituto Universitario de Ciencias de la Educación. Madrid: Universidad Autónoma de Madrid.

Eilman, M. E., \& Saruwatari, L. R. (1979). When beauty is beastly: The effects of appearance and sex on evaluations of job applicants for managerial and nonmanagerial jobs. Organizational Behavior and Human Performance, 23, 360-372.

El Pais. (2010). Muy guapa para ser banquera (Too pretty to a banker). 3rd June.

Elliott, J. R., \& Ryan, A. S. (2004). Race, gender, and workplace power. American Sociological Review, 69(3), 365-386.

Grant, W. V., \& Eiden, L. J. (1982). Digest of education statistics. IAIL Washington, DC: National Center for Education Statistics. (ERIC Document Reproduction Service No. ED 225 272)

Infante, E. (2011). Researching work-family discourses: Step-by-step audiovisual analysis of the British sitcom only fools and horses (1981-2003). Newcastle upon Tyne, UK: Cambridge Scholars Publishing.

Infante, E. (2015). (Coord.). Manual SHINING de atención a las altas capacidades intelectuales (SHINING Handbook on attention to intelectual high skills). Sevilla: Editorial Aconcagua Libros.

Kerr, B. A. (1985). Smart girls, gifted women. Columbus, OH: Ohio Psychology Publishing Company.

Kerr, B. A., \& Cohn, S. J. (2001). Smart boys: Talent, manhood and the search for meaning. Scottsdale, AZ: Great Potential Press. Kline, B. E., \& Short, E. B. (1991). Changes in emotional resilience: Gifted adolescent females. Roeper Review, 13, $118-121$.

Lips, H. (2006). A new psychology of women (3rd ed.). Boston: McGraw-Hill.

Maume, D. J. Jr. (1999). Glass ceilings and glass escalators. Occupational segregation and race and sex differences in managerial promotions. Work and Occupations, 26(4), 483-509. 
Ortner, S. (1974). Is female to men as nature to culture? In M. Z. Rosaldo and L. Lamphere (Eds.), Women, culture, and society. USA: Standford University Press.

Osca, A., \& López-Sáez, M. (1994). Desarrollo de carrera y género. Factores que influyen en las diferencias entre hombres y mujeres (Career and gender development. Influencing factors in men and women differences). Psicología del Trabajo y de las Organizaciones, 28(10), 73-85.

Peiró, J. M., Prieto, F., \& Roe, R. A. (1996). La aproximación psicológica al trabajo en un entorno laboral cambiante (A psychological approach to work in a changing labour context). In J. M. Peiró and F. Prieto (Eds.), Tratado de Psicología del Trabajo (Handbook of work psychology, Vol I: La actividad laboral en su contexto, pp. 15-36). Madrid: Síntesis.

Reis, S. M. (1998). Work left undone: Compromises and challenges of talented females. Mansfield Center, CT: Creative Learning Press.

Reis, S. M., \& Callahan, C. M. (1989). Gifted females: They have come a long way-or have they? Journal for the Education of the Gifted, 12(2), 99-117.

Roeper, A., \& Silverman, L. K. (2009). Giftedness and moral promise. In D. Ambrose and T. Cross (Eds.), Morality, ethics, and gifted minds (Chapter 19, pp. 251-264). Lawrenceville, NJ: Roeper Review.

Rosaldo, M. Z. (1980). The use and abuse of Anthropology. Signs, 5(3).

Sacks, K. (1979). Engels revisado: Las mujeres, la organizacion de la produccion y la propiedad privada (Engels revisited: Women, organisation of production, and private property). In O. Harris and K. Young (Eds.), Antropologia y feminismo. Barcelona: Anagrama.

Schein, V. E. (1973). The relationship between sex role stereotypes and requisite management characteristics. Journal of Applied Psychology, 57, 95-100.

Shaffer, D. R. (1988). Social and personality development (2nd ed.). Pacific Grove, CA: Brooks/Cole.

Silverman, L. K. (1995). To be gifted or feminine: The forced choice of adolescence. The Journal of Secondary Gifted Education, 6 , 141-156.

Silverman, L. K., \& Miller, N. B. (2009). A feminine perspective of giftedness. In L. Shavinina (Ed.), The international handbook on giftedness (pp. 99-128). Amsterdam: Springer Science.

Storek, J. S. (2011). The hubris and humility effect and the domain-masculine intelligence type: Exploration of determinants of gender differences in self-estimation of ability (Doctoral thesis, UCL, University College London).

Taliff, E. M. (1991). Personnel selection and physical attractiveness: An examination of the effects of candidate physical attractiveness in personnel selection in education (Doctoral dissertation, Pennsylvania State University, 1991). Dissertation Abstracts International, 52(4), 1170.

Webster, N. (1979). Webster's deluxe unabridged dictionary (2nd ed.). New York: Simon \& Schuster.

Wirth, L. (2001). Breaking through the glass ceiling: Women in management. Genf: International Labour Organization.

Wolf, N. (1991). The beauty myth. How images of beauty are used against women. London: Vintage Books. 